will prevent their attacks, and the Government Entomologist is of opinion that a reliable tick-dip must contain arsenic, the nonpoisonous preparations living up to their names when used against ticlis.

At certain stages of their life cycle, i.e., when moulting, the tick is almost invulnerable to any sort of dip, the double skin acting as a shield and protection.

At the Inter-Colonial Veterinary Conference the following scheme of preventive measures was recommended:-

The disease not as yet existing in Cape Colony, the Conference recommended that measures for the eradication of African Coast fever be taken only by the Transvaal in their affected districts and in matters of boundry tences, the other Governments of South Africa to contribute towards the expense.

All affected cattle to be slaughtered without compensation, and the disinfection of hides and carcases to be carried out.

In contact animals to be dipped and moved, or, at the discretion of the veterinary officer, slaughtered, and compensation given at a fixed tariff; place of slaughter to be also at the discretion of the veterinary surgeon who supervises disinfection, etc.

All infected areas to be cleared of cattle for eighteen months, and any cattle straying into such areas to be immediately destroyed without compensation.

Burning of the grass was strongly recommended.

It was estimated that the number of cattle destroyed in carrying out this scheme would not exceed 10,000 , and the probable cost $£ 50,000$, but this will not include the cost of veterinary and police supervision.

The Transvaal, Natal, and Swaziland border to be fenced (cost estimated at $f(0,000)$, and a one mile police patrol belt to be instituted.

The cost of carrying out these plans to be borne by the various Colonies, and its distribution based on the number of horned cattle in each State as given in the recent census returns.

\title{
JAGZIEKTE OR CHRONIC CATARRHAL PNEUMONIA (SHEEP).
}

By WM. Robertson, M.R.C.V.S., Bacteriologist to the Department of Agriculture, Cape Town.

THERE is a disease affecting the lungs of sheep during the winter months in the upland parts of this Colony to which the Chief Veterinary Surgeon has given the name of chronic catarrhal pneumonia, and which is known locally as "jagziekte."

It accounts for a considerable number of animals every year, and from its characteristic lesions I am inclined to think it is due to some specific cause other than exposure to cold and wet.

It is a peculiar form of pneumonia, inasmuch as the hardening and consolidation of the lungs described below is not preceded by the 
usual stages of congestion, hepatisation, etc., and there is an almost entire absence of fever.

Symptons. - The first symptom usually noticed is a cough, with marked shortness in depth and increase in number of respirations. These symptoms as the disease progresses simply increase in severity, until the least movement causes the animal to pant for breath, heave at the flanks, and lie down completely exhausted.

It is this heaving of the flanks and hurried breathing which gave rise to the Colonial name of "jagziekte," from "jagt," the Dutch to drive, and "ziekte," a sickness. The animal looks as if it had been over-driven, and that is quite the impression a casual observer might get if he saw two or three affected sheep trailing after the flock. Another Colonial name is "hartslagziekte," the "hartslag" being a general name for the heart, lungs, and liver, i.e., the pluck.

The course of the disease is more rapid in winter than in summer, and careful treatment and nursing undoubtedly prolong the animal's life.

I have had an animal under observation in a shed for seven months which, though slightly affected when brought in, gradually grew worse and worse, until it undoubtedly died from want of lung area.

Treatment.-The Chief Veterinary Surgeon shares the opinion as to its contagious nature, and recommends the slaughter of all affected animals.

Post-mortem Appearances.-It is not easy to obtain good, that is, advanced post-mortems, as the sheep-farmer usually slaughters a sheep whenever anything is noticed wrong with the breathing and uses the flesh, but the following are the post-mortem appearances in a moderate case of the disease.

The lungs and their attendant lymphatic glands are alone affected; the latter are enlarged, pale, and odematous. The lungs show more or less extensive areas of consolidation; sometimes there seems one centre or area of infection, but other cases seem to indicate that the infection has started from many centres. The affected part is quite solid, of a darker colour than normal lung, firm, friable, and slippery to the touch. In some cases the affected part cuts like bacon, and the cut surface has a soapy, greasy, feeling to the fingers. In advanced cases fibrous tissue may form to such an extent that the affected part of the lung cuts like cartilage. The bronchi persist, but the lumen is often occluded. The consolidated portions do not appear either congested or swollen. On squeezing the cut surface a quantity of froth and débris oozes from bronchi. The plugged air cells do not empty when scraped. Sometimes on section the plugged bronchi stand out like tubercles, and the lungs may be as dry as cartilage.

In typical cases of this disease there does not appear to be any tendency towards breaking down of the lung tissue or formation of abscesses.

"The pleura is not affected in the early stage, but after the disease has extended so as to involve a considerable portion of the lung the pleura over the affected part becomes thickened, and inflammatory adhesions form between the lung covering and the lining of the ribs. The great majority of the affected animals die, though many linger on for months if allowed to do so" (D. Hutcheon).

One thing which strikes an observer at a post-mortem is the sharp 
line of demarcation between comparatively healthy and completely consolidated lung. This is seen in Fig. 3 (Plate VII.); here the almost occluded air cells and bronchi approximate in the same field to what is only slightly affected tissue.

Microscopical Examination.-The lesion as shown under a low power (Figs. 2 and 3, Plate VII.) is that of catarrhal pneumonia. The alveoli are plugged with an exudate which consists almost entirely of proliferated cells from the alveolar lining, mixed with a few leucocytes.

The affection appears to spread steadily from sick to healthy lung.

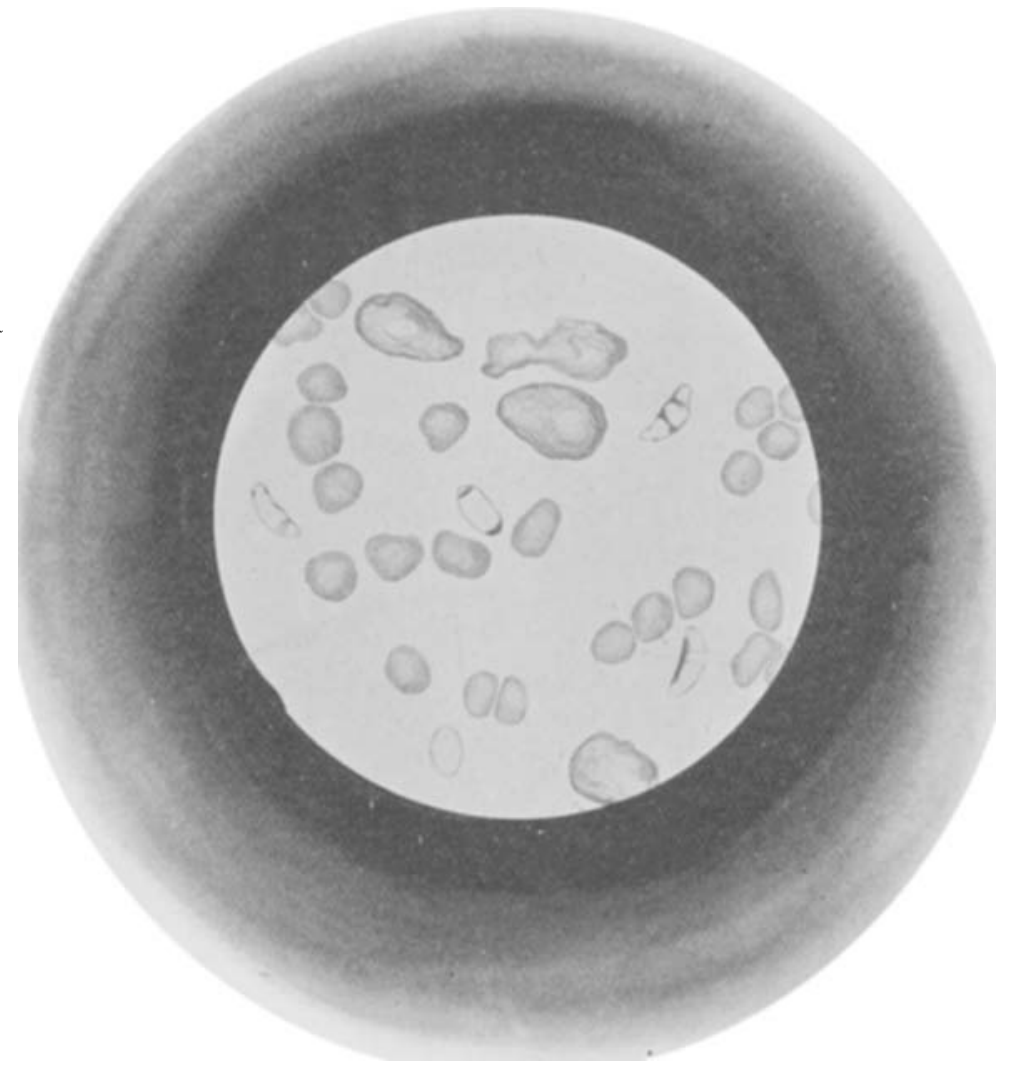

Composite drawing from three fields, showing crescent-shaped bodies (Leitz ${ }_{1}^{\mathrm{t}}$ oil imm., No. 4 comp. ocular).

While examining smears from affected lungs I have noticed the presence of a body which I take to be of a parasitic nature. I am unable to find it in healthy lungs or in healthy parts of lungs which show areas of the disease. This parasite is a crescent-shaped body with rounded ends, about twice the diameter of a red blood corpuscle in length, with a centre which takes the stain deeply in the form of a band, and in certain particulars recalls the crescentic forms of human malaria (Laverans bodies).

Another body which I take to be a different stage of the same para- 
site is a small cylinder with rounded ends, resembling a segment of a ruler.

These parasites are rather sparing in number, and very difficult to stain. For some time I was attracted by what I thought were vacuoles or grease globules; these were the parasites which did not take the stain.

I stain with warm carbol-fuchsin for twenty minutes, then soak in weak spirit and water.

The bodies I describe, though I do not claim them to be the causal parasite of the disease, are of sufficient interest to warrant a description. I take them to belong to the sporozoa, members of which group are credited with pathogenic characters.

Rixford and Gilchrist describe in detail two cases of Protozoon infection of the skin (John Hopkin's Hospital Report, Vol. I., page 209, I 896), and the bodies seen in this chronic cattarrhal pneumonia may be the cause of the lesions just described.

In conclusion, I may state that up to the present I have failed completely to convey the disease from sick to healthy animals by cohabitation, feeding, and all varieties of inoculation methods, both with blood and affected tissues.

This disease I think is mainly worth note because of its insidious progress and incurability, and because it shows no tendency for the affected parts of the lung to undergo degeneration, caseation, or the formation of abscess.

\section{DESCRIPTION OF PLATE VII.}

\section{African Coast Fez'er.}

FIG. I. Exact reproduction of a microscopic field in a blood film from an advanced case of African Coast fever. Stain azure II. and eosin. Zeiss $\frac{1}{1}$ oil imm., ocular 4 (see p. 2 I 7 ).

$$
\text { Jagzickte. }
$$

FIG. 2. Section of badly affected lung, showing complete blocking of the alveolı with proliferated epithelium.

FIG. 3. Section showing junction of badly affected and comparatively healthy lung tissue.

\section{M M U NTY: ${ }^{1}$}

By William Bulloch, M.D., Bacteriologist to the London Hospital, E.

THE advent of the bacteriological era in medicine twenty-five years ago revived the old question whether resistance to the invasion of infectious virus is brought about by the body humours or the body cells, and just as the old humoral doctrines preceded Virchow and his cellular pathology, so here the humoral doctrines are chronologically the first. In dealing with the question of the relation of the cells and fluids to the immunity problem - a problem which for interest to the 